\title{
Hybrid Control of PV-FC Electric Vehicle using Lyapunov based Theory
}

\author{
Saad Hayat ${ }^{1}$ \\ SEECS,NUST \\ Islamabad,Pakistan
}

\author{
Mehtab Qureshi ${ }^{5}$ \\ Hajvery University \\ Lahore, Pakistan
}

\author{
Sheeraz Ahmed ${ }^{2}$ \\ Iqra National University \\ Peshawar, Pakistan
}

\author{
Zeeshan Najam ${ }^{6}$ \\ Ultimate Consultancy \\ Peshawar, Pakistan
}

\author{
Tanveer-ul-Haq ${ }^{3}$ \\ University of Science and Technology \\ Bannu, Pakistan
}

\author{
Sadeeq $\operatorname{Jan}^{4}$ \\ Department of CS and IT, UET \\ Peshawar, Pakistan
}

\begin{abstract}
Lyapunov based control is used to test whether a dynamical system is asymptotically stable or not. The control strategy is based on linearization of system. A Lyapunov function is constructed to obtain a stabilizing feedback controller. This paper deals with Lyapunov based control of multiple input single output system for hybrid electric vehicles (HEVs). Generally, an electric vehicle has an energy management system (EMS), an inverter, a DC-DC converter and a traction motor for the operation of its wheels. The control action is applied on the DC-DC converter, which works side-by-side with the EMS of the electric vehicle. The input sources considered in this study are: photo-voltaic (PV) panel, fuel cell and high voltage lithiumion (Li-ion) battery. PV cell and fuel cell are considered as the primary sources of energy and the battery is considered as the secondary source. The converter used is a DC-DC boost converter which is connected with all the three sources. The idea follows the basic HEV principle in which multiple sources are incorporated to satisfy the power demands of the vehicle, using a DC-DC converter and an inverter, to operate its traction motor. The target is to achieve necessary tracking of all input source currents and output voltage, and fulfill the power demand of the HEV under severe load transients. The operations of the DCDC converter are divided into three stages, each representing a different combination of the input sources. The analysis and proof of the stability of the HEV system is done using the Lyapunov stability theory.The results are discussed in the conclusion.
\end{abstract}

Keywords-Energy Management System (EMS); Hybrid Electric Vehicle $(\mathrm{HEV}) ; \mathrm{DC}-\mathrm{DC}$ converter; Multiple Input-Multiple Output (MIMO) system

\section{INTRODUCTION}

Renewable energy has been the center of attraction for past three decades. Nowadays, HEVs are being considered as a great tool for transportation, which can utilize the renewable energy, coming in from many different sources. Thus, a new form of automobile industry revolution is taking place. Hybrid Electric vehicles (HEVs) have been already adapted and have presented encouraging results [1], [2].

Although at present, commercial electric vehicles are using a hybrid of a renewable energy source (such as a fuel cell or PV cell) with an internal combustion engine (ICE), but recently a more hybridized form of HEVs has taken place. This new form of HEV incorporates several sources at the same time. Fuel Cell, battery, super capacitor and PV cells

\author{
Zahid Wadud $^{7}$ \\ Department of Computer System Engg \\ UET Peshawar, Pakistan
}

are such examples which can simultaneously provide energy to the HEV.

Today, HEVs are using the fuel cell and a battery as its sources to save energy. Energy savings benefit both the consumers and grid. There is less burden on grid, electric vehicles range is increased and maintenance of fuel cell is reduced [3], [4]. It has been found that an electric vehicle which interconnects FC and battery, with or without any other kind of other source, is the most effective way to cater demand [5]. Solar energy is best alternative energy source for this scenario. With PV cell, fuel cell and battery, we can be more effective with fuel savings, alleviating noise and providing a pollutant free environment, and at the same time, fulfilling the limitations of both fuel cell and battery [6]. For such a system where more than one source is providing energy, DC-DC converters are necessary for its operation [7]. A lot of work done has been done in improving the performance and efficiency of the DC-DC converters for electric vehicles.

Fuel cell based electric vehicles (FCEVs) are environmentally friendlier than the conventional ICE based HEVs because they have zero carbon emission as FCEVs use hydrogen fuel and oxygen (from air) to produce only electricity and water as a by-product. Proton Exchange Membrane Fuel Cell (PEMFC) is a type of FC, which has a high efficiency and low operating temperature. Therefore, they are mostly used in HEVs nowadays [8], [9]. Although fuel cells are a good candidate for an HEV's energy source, they don't have fast standby operation i.e. they have a lesser power density than other electrical sources like battery or super capacitor [10]. In other terms, it means that PEMFC cannot provide sufficient energy during load transients. Another flaw in using PEMFCs in HEVs is the manufacturing costs and durability issues which are inevitable when one deals with fuel cells [11]. Hence a battery has to be used with fuel cell to overcome these problems.

Recently, solar photo voltaic energy is introduced in automobile industry due to many reasons such as being cost effective, pollution free and durable in the long run [12]. The lifetime of PV cells (or modules) are commonly up to 20 years, which is far better than other electrical sources like battery. Furthermore, solar energy can be easily converted to electrical energy using DC-DC converters. However, when 
using PV cells, factors such as unreliability and cost of solar cells, should always be considered. Another important factor is the maximum power that can only be obtained from PV cell when it is operating at its maximum power point (MPP). A number of strategies have been used in various studies to evaluate the MPP of the PV [13].

HEVs also require rechargeable batteries to aid the driving mechanism and store energy, obtained from regenerative braking. Therefore high capacity batteries and higher capacity power converters are needed for this operation [14]. Another important use of batteries, installed in an FCEV, is the support they provide to the primary power source: FC. In an FCEV, fuel cells (FCs) require batteries or super capacitor whenever there is a sudden load transient. In case of high power demand, batteries and FC simultaneously provide power to the load and during regenerative braking, the extra power can be used to recharge the batteries. The main reason is that FCs have poor transient response to these sudden spikes; But they have more driving range than battery electric vehicles (BEVs) because BEVs only contain batteries as their power source. Since, batteries have a limited amount of charge in them, they require recharging after some time. In FCEVs, FC has a greater energy density (amount of energy stored) than a battery pack, hence they can provide energy as long as they are provided with the hydrogen fuel.

In an $\mathrm{HEV}$, multiple input sources require a power unification scheme of at least two or three power sources at the same time [15]. The combination of the active sources solely depends on the HEV's load demand and our control strategy which is operated through the EMS. The reason is that the solar energy is not available at all times and FC's slow response time to transients require a battery. The battery has disadvantages like less driving range and slow charging time as compared to FC. Hence we need collaboration of two or more than two sources for a complete and successful operation of the HEV [16].

The DC-DC converter acts as an interface between PV source, fuel cell and battery. DC-DC converter is used in electric vehicle for regulating the output voltage and sources current [17]. A system where sources of different kinds interact with each other and the load, is called a hybrid energy storage system (HESS). A HESS requires the EMS for its operation. The EMS usually contains an algorithm for providing different reference values to the controller and decide which stage or mode should be operated. However, in this study our primary focus is on the working and control of the HESS. This includes the selection of the DC-DC converter topology and its benefits and the selection of suitable power sources for the HEV.

a) Literature Review: In [18], a control technique has been applied on the HEV to design observers for estimating the values of speed and torque. Several control strategies have been developed for fast charging of electric vehicles in [19]. An optical isolation is introduced between the three sources in [20]. It uses a battery charger and a DC-DC converter as the combined charger. This scheme ensures unified power transmission between the sources. The HESS of an HEV requires power factor correction [21], getting high voltage gain and regulating the current flow inside the battery [22]. Model Predictive Control is another form of advanced control technique which is extensively applied on converters [23]-[25]. The problem with MPC is that it causes a lot of computational burden and it can't be applied on all systems. A number of control techniques, both linear and non-linear, have been applied to HESS since its first introduction. Linear control techniques include fuzzy and PI based control [26], [27]. In [28], a PI controlled bi-directional DC-DC converter has been used to drive DC motor of a BEV. Although the PI control provides a simple control approach, it fails to provide a steady, ripple-free output. In [29], a closed loop controller using decoupling method has been introduced to design a closed loop compensator. Battery balancing is also an important aspect for EVs which is achieved by constant current flow, described in [30]. This study uses a battery balancing circuit for Li-ion battery, using a single inductor based circuit for HEVs. PI control is also used in this study. For control of capacitor and battery currents PID control is used in [31]. The unwanted noise can be found in tracking of all these strategies.

As we know that most dynamic systems in real world exhibit nonlinear characteristics. This fact also extends to DC-DC converters, fuel cells [32], [33] and PV cells [34]. Linear systems are usually constructed by linearization of the system dynamics around one equilibrium point. It is obvious that this linear mathematical model is not rich enough to describe many commonly observed phenomena of non-linear systems. This is why when linear control is applied to a nonlinear control system it results in very limited operating range [35] and sometimes poor performance.

The formulation of paper is as follows: In Section III working principle of HESS is explained. Controller analysis is presented in Section IV. In Section V, the stability analysis of the closed loop system is done. In Section VI, simulation results are presented and analyzed. In Section VII, the proposed controller is compared with PI-based controller on the same HESS, and lastly, the conclusion of paper is presented in Section VIII.

\section{Motivation}

The sale of Electric Vehicles have been moderate due to consumers not acknowledging the benefits provided to them. Conventional electric vehicles offer more interesting package and have less uncertainty such as battery life, range of vehicle and speed of technological improvement [2].

The only method of tackling this issue is by combining power electronics with a well devised control system which will guarantee long range, longer battery life and performance optimization.

Control system designed in [29] has overshoot and ripple of large magnitude found in output voltage response and inductor current which impacts the battery life and performance causing considerable power loss. If a control system is devised such that there is perfect tracking of required output voltage at load side and current flowing through the inductors with little to no ripple, this will help the cause. The power electronics 


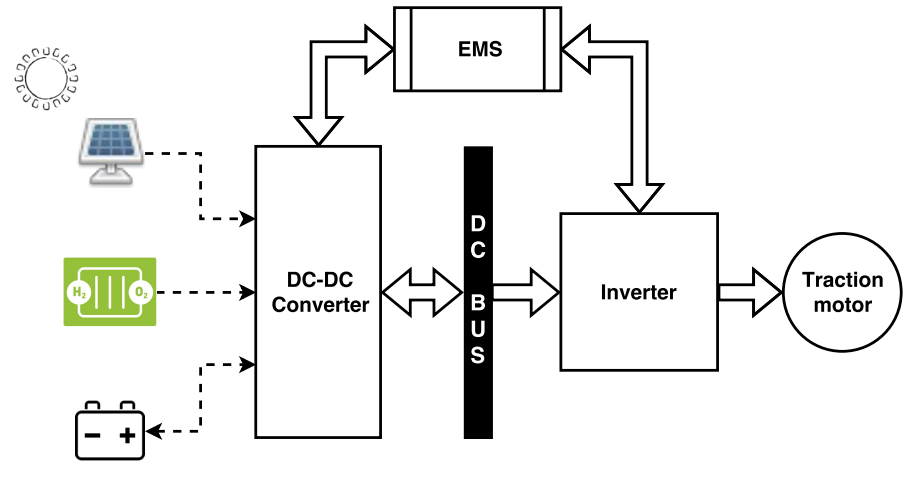

Fig. 1. General structure of HEV

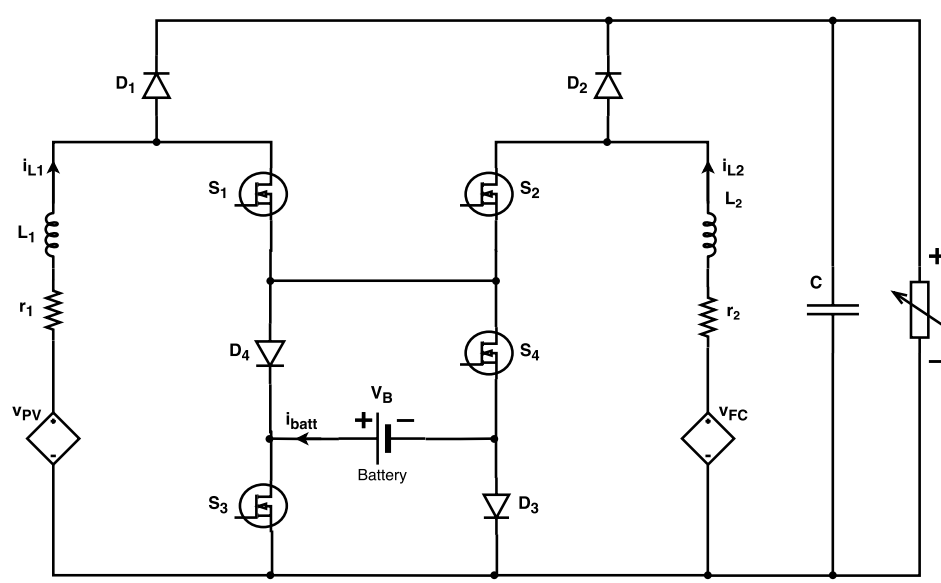

Fig. 2. Selected DC-DC converter schematic

circuitry in [15] is complicated due the adoption of two power converters at a some time which makes management from control side difficult, added cost due to increased number of elements and package bulky.

\section{DEMONSTRATION OF HESS AND CONVERTER TOPOLOGY}

Fig. 1 shows the selected HEV which includes EMS, traction motor, inverter, DC-bus, DC-DC converter and the three sources. Input sources include PV cells, high voltage battery and PEMFC. Energy direction is planned such that the energy transfer is uni-directional between PEMFC and load i.e. from PEMFC to load, because PEMFC cannot be recharged by conventional means. Similar is the case beween PV source and load. For batteries, the transfer of energy is selected as bi-directional because in case of load transients, the battery pack has to be charged and discharged. These energy transfers are later explained in subsection III-A.

Fig. 2 shows the considered HESS for the HEV. The converter used is three input DC-DC boost type. The two input sources, $\mathrm{PV}$ and $\mathrm{FC}$, have voltages $v_{P V}$ and $v_{F C}$ respectively. The battery voltage is taken as $V_{B}$. Both $v_{P V}$ and $v_{F C}$ are shown as dependent voltage sources because the PV source voltage depends on the PV current, light intensity and ambient temperature of the PV panel, whereas, the fuel cell (FC) voltage depends on the FC current. Since both the input sources are in series with the inductors $L_{1} \&$ $L_{2}$, the current in $i_{L_{1}}$ is $i_{P V}$ and the current in $i_{L_{2}}$ is $i_{F C}$. Hence, the voltage sources indirectly depend on the inductor currents. Capacitor $C$ is output filtering capacitor and $R_{L}$ is the variable load representing the inverter and the traction motor load. Four switches $S_{1}, S_{2}, S_{3}$ and $S_{4}$ are used in this converter. All of them are independently controlled by duty cycles $d_{1}, d_{2}, d_{3}$ and $d_{4}$ respectively.

The combination of the duty ratios are set in such a way that ensures the converter always works in continuous conduction mode (CCM). This is done to minimize the current ripples as much as possible. The converter topology used in this paper is taken from [29] in which a PI control technique has been applied.

\section{A. Hybrid Energy Storage System (HESS)}

As stated earlier, the HESS is a power conditioning unit in an HEV, which ensures a unified power flow between the energy sources and synchronization of the power sources with -the DC-DC converter and load. Usually, the HESS comprises of a DC-DC converter and/or a DC-AC converter, and an EMS, that contains a set of rules that are necessary to operate the HEV. A mathematical model of the selected HESS is developed in this section. Also, the highlights of the EMS operation are described in detail.

1) DC-DC Converter Mathematical Modeling: The converter structure is shown in Fig. 2. The converter operates in three stages. In the first stage, only $v_{P V}$ and $v_{F C}$ power up the load while the battery $v_{B}$ is disconnected i.e. it neither charges or discharges. In the second stage, all three energy sources provide power to the load. In the third stage, $v_{P V}$ and $v_{F C}$ supply the power to the load while battery $v_{B}$ is recharged. For simplicity, all switches are considered ideal and the equivalent series resistance (ESR) of the capacitor $(C)$ is considered negligible. Dynamic equations for each stage are evaluated using volt-second and charge-second balance. For the derivation of the mathematical model for this DC-DC converter, the large-signal model is being considered.

The three stages of the DC-DC converter, described above, can be represented by the state of the battery current $i_{\text {batt }}$ in each stage. It can be given as:

$$
i_{\text {batt }}= \begin{cases}0, & (\text { Stage 1) } \\ +v e, & (\text { Stage 2) } \\ -v e, & (\text { Stage 3) }\end{cases}
$$

Since, there are three energy storing elements in the DCDC converter, there would be three state variables for this system:

$$
\left[\begin{array}{lll}
x_{1} & x_{2} & x_{3}
\end{array}\right]^{T}=\left[\begin{array}{ll}
<i_{L_{1}}> & <i_{L_{2}}>\quad<V_{o}>
\end{array}\right]^{T}
$$

These state variables are respectively, inductor 1 current $i_{L_{1}}$, inductor 2 current $i_{L_{1}}$ and output voltage $V_{o}$. The state 
variables are taken in their state-averaged form because the mathematical model is also state-averaged.

2) STAGE $1\left(i_{\text {batt }}=0\right)$ : From Fig. 3, it can be seen that there are 3 modes of the converter in this stage. Since the system is operating without battery, the inductors $L_{1} \& L_{2}$ are powered-up by $v_{P V}$ and $v_{F C}$, through paths $S_{1}-S_{4}-D_{3} \&$ $S_{2}-S_{4}-D_{3}$ respectively. In the next mode, switch $S_{1}$ is turned off and the diode $D_{1}$ becomes forward-biased. Therefore, $v_{P V}$ provides power to the load along with $i_{L_{1}}$. In the third mode, switch $S_{2}$ is turned off and both sources $v_{F C} \& v_{P V}$ simultaneously provide power to the load. By applying voltsecond and charge-second balance, the converter equations for a single switching cycle would be:

$$
\begin{aligned}
\frac{d i_{L_{1}}}{d t} & =\frac{1}{L_{1}}\left[d_{1} v_{P V}+\left(1-d_{1}\right)\left(v_{P V}-V_{o}\right)-r_{1} i_{L_{1}}\right] \\
\frac{d i_{L_{2}}}{d t} & =\frac{1}{L_{2}}\left[d_{2} v_{F C}+\left(1-d_{2}\right)\left(v_{F C}-V_{o}\right)-r_{2} i_{L_{2}}\right] \\
\frac{d V_{o}}{d t} & =\frac{1}{C}\left[\left(1-d_{1}\right) i_{L_{1}}+\left(1-d_{2}\right) i_{L_{2}}-\frac{V_{o}}{R_{L}}\right]
\end{aligned}
$$

3) STAGE $2\left(i_{\text {batt }}>0\right)$ : In this stage, all the sources: $v_{P V}, v_{F C} \& V_{B}$ power up the load. By inspecting the circuit in Fig. 4, it can be seen that there are 4 operating modes of the converter in this stage. In the first mode, the battery $V_{B}$ first discharges and together with the sources $v_{P V}$ and $v_{F C}$, power-up the inductors $L_{1} \& L_{2}$. Since, the battery charge is depleted at the end of this mode, the next modes are almost similar to the three modes of stage 1 because $i_{\text {batt }}$ remains zero after the first mode. By applying volt-second and chargesecond balance, the converter equations for a single switching cycle would be:

$$
\begin{gathered}
\frac{d i_{L_{1}}}{d t}=\frac{1}{L_{1}}\left[\left(d_{1}-d_{4}\right) v_{P V}+d_{4}\left(v_{P V}+V_{B}\right)\right. \\
\left.+\left(1-d_{1}\right)\left(v_{P V}-V_{o}\right)-r_{1} i_{L_{1}}\right] \\
\frac{d i_{L_{2}}}{d t}=\frac{1}{L_{2}}\left[\left(d_{2}-d_{4}\right) v_{P V}+d_{4}\left(v_{F C}+V_{B}\right)\right. \\
\left.+\left(1-d_{2}\right)\left(v_{F C}-V_{o}\right)-r_{2} i_{L_{2}}\right] \\
\frac{d V_{o}}{d t}=\frac{1}{C}\left[\left(1-d_{1}\right) i_{L_{1}}+\left(1-d_{2}\right) i_{L_{2}}-\frac{V_{o}}{R_{L}}\right]
\end{gathered}
$$

4) STAGE $3\left(i_{\text {batt }}<0\right)$ : In this stage, $v_{P V}, v_{F C}$ power-up the load and also charge the battery $V_{B}$. There are 4 modes of converter operation in this stage, which can be seen in Fig. 5. In this mode, $V_{P V}$ and $V_{F C}$ are charging the inductors and the output capacitor $C$ is providing power to the load. In the second mode, the sources $v_{P V}$ and $v_{F C}$ are charging the battery source $V_{B}$ through the common path $D_{4}-V_{B}-D_{3}$. In the third mode, the source $v_{P V}$ provides power to the load and replenish the charge of output capacitor $(C)$, whereas the source $v_{F C}$ keeps charging the battery $V_{B}$. Once the battery $V_{B}$ is recharged, the two input sources $v_{P V}$ and $v_{F C}$ start delivering power directly to the load. By applying volt-second

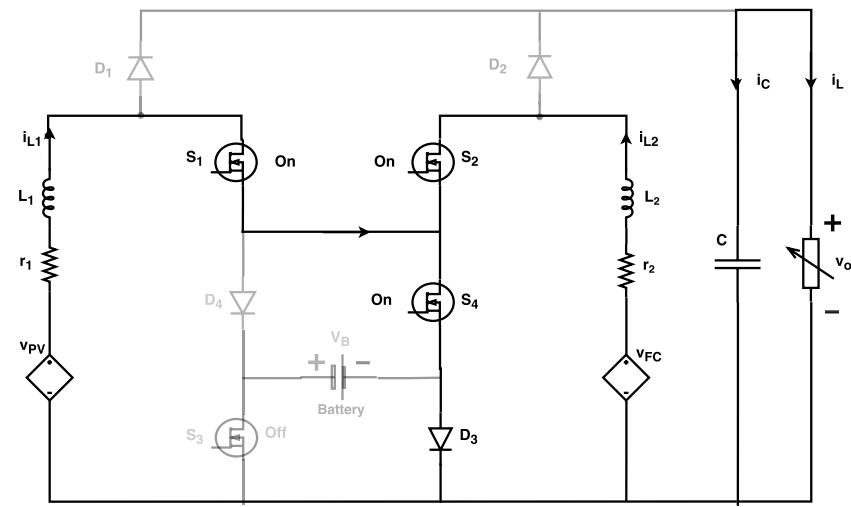

(a)

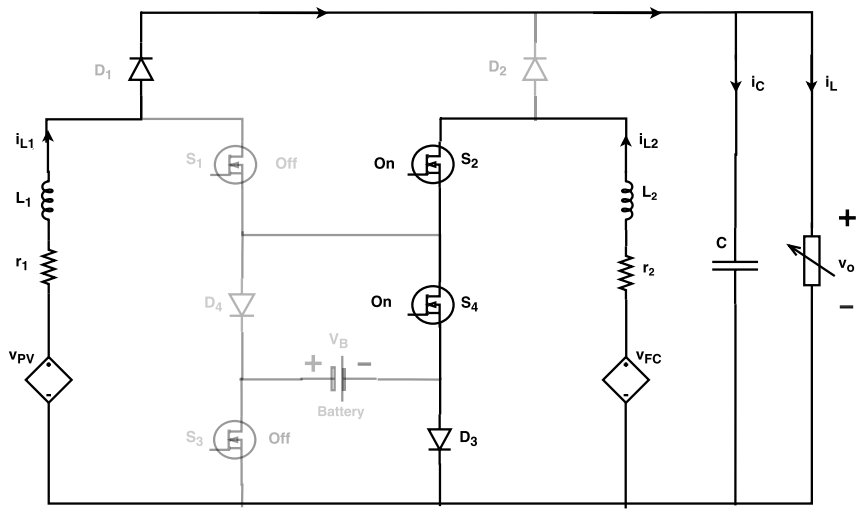

(b)

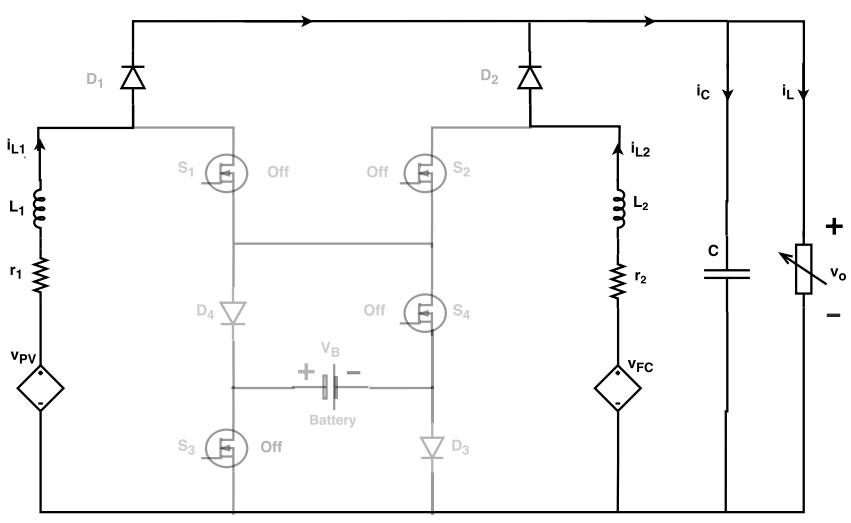

(c)

Fig. 3. Stage 1 of the DC-DC converter

and charge-second balance, the converter equations for a single switching cycle would be:

$$
\begin{aligned}
& \frac{d i_{L_{1}}}{d t}=\frac{1}{L_{1}}\left[\left(d_{1}-d_{4}\right) v_{P V}+d_{4}\left(v_{P V}+V_{B}\right)\right. \\
& \left.+\left(1-d_{1}\right)\left(v_{P V}-V_{o}\right)-r_{1} i_{L_{1}}\right] \\
& \frac{d i_{L_{2}}}{d t}=\frac{1}{L_{2}}\left[\left(d_{2}-d_{4}\right) v_{P V}+d_{4}\left(v_{F C}+V_{B}\right)\right. \\
& \left.+\left(1-d_{2}\right)\left(v_{F C}-V_{o}\right)-r_{2} i_{L_{2}}\right] \\
& \frac{d V_{o}}{d t}=\frac{1}{C}\left[\left(1-d_{1}\right) i_{L_{1}}+\left(1-d_{2}\right) i_{L_{2}}-\frac{V_{o}}{R_{L}}\right]
\end{aligned}
$$




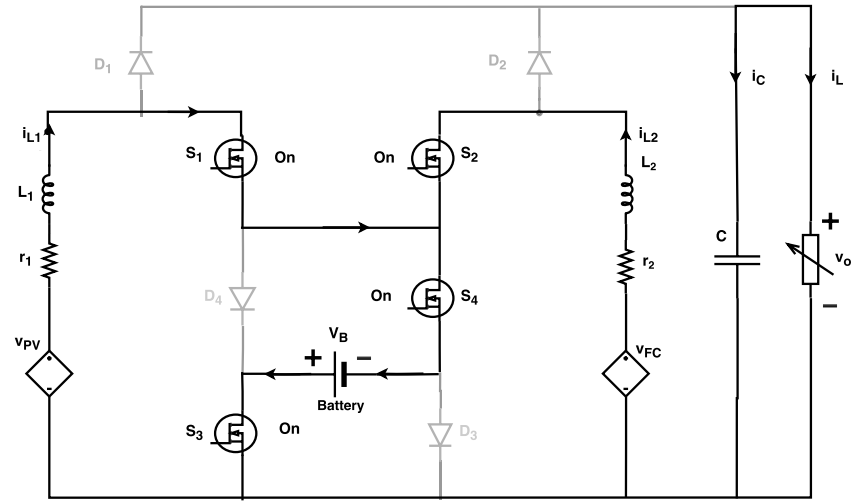

(a)

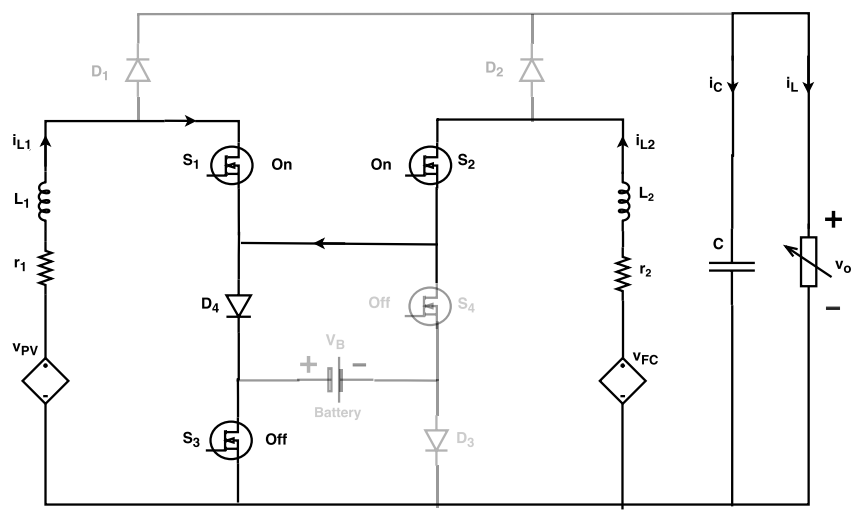

(b)

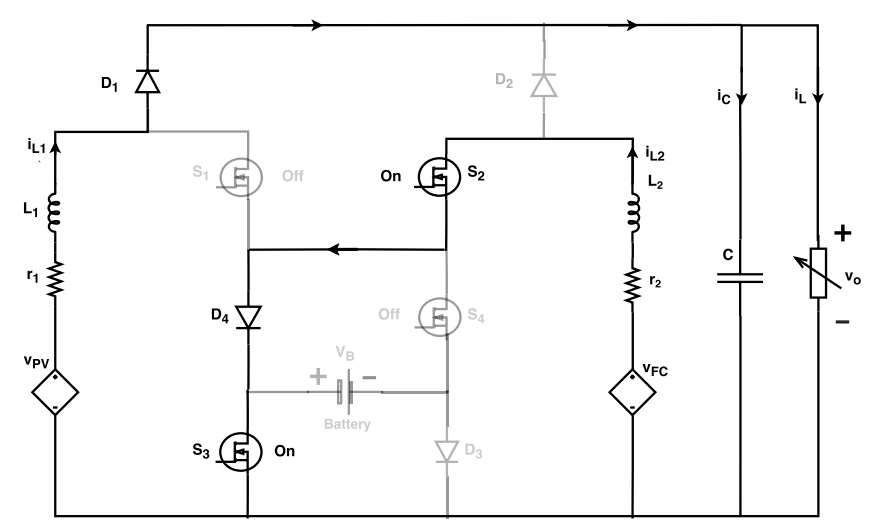

(c)

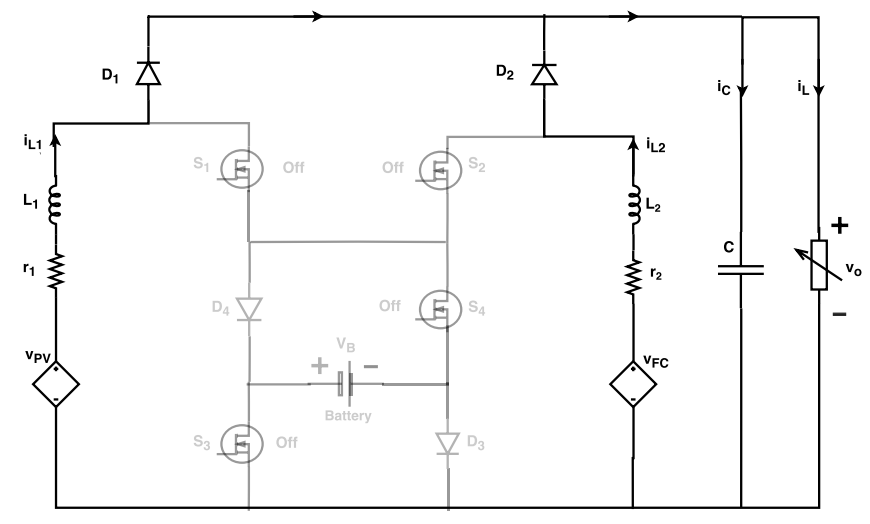

(d)

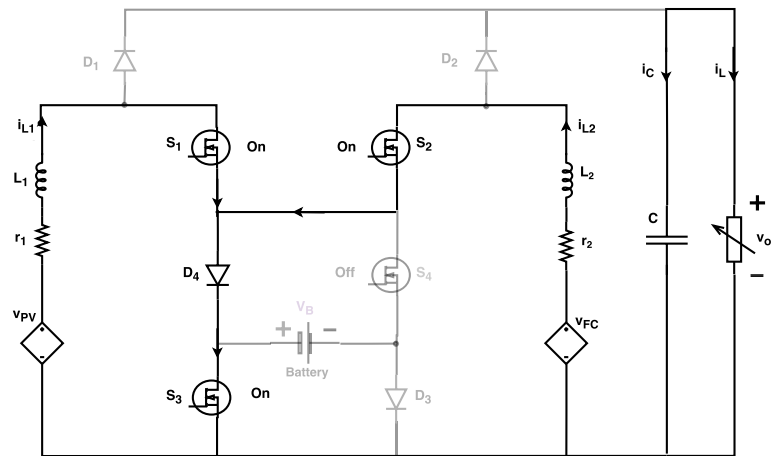

(a)

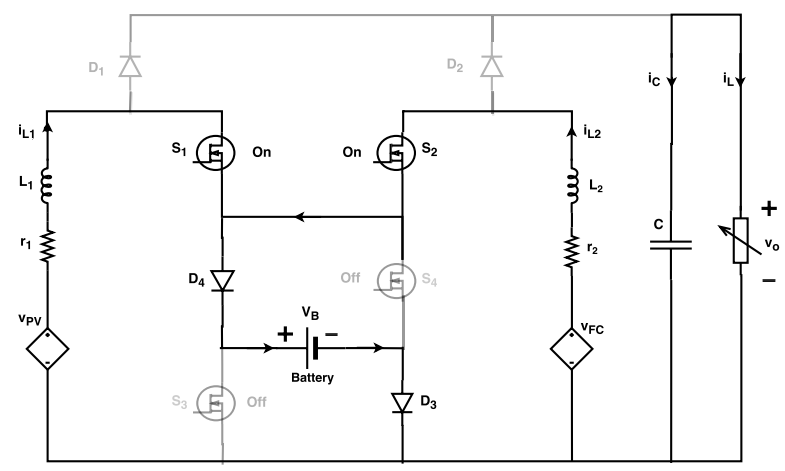

(b)

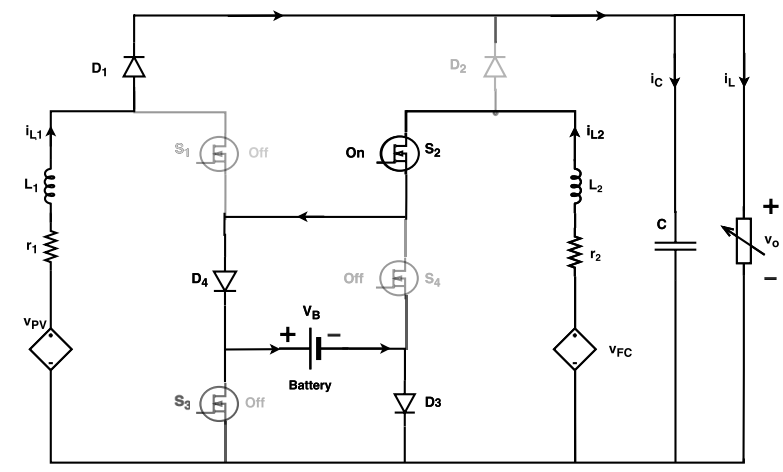

(c)

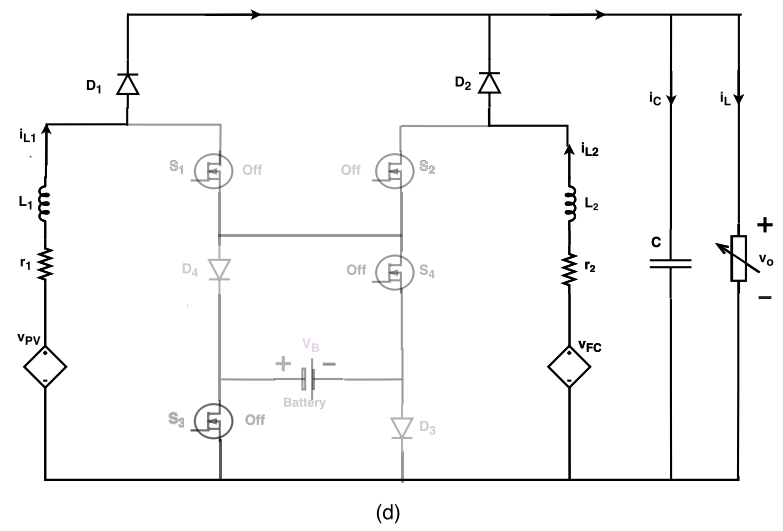

Fig. 5. Stage 3 of the DC-DC converter 
From the dynamic equations 3-b, 3-c \& 3-d and the state variables taken as $i_{L_{1}}=x_{1}, i_{L_{2}}=x_{2}$ and $V_{o}=x_{3}$, the mathematical model for each stage is given as follows:

\section{FIRST STAGE:}

$$
\begin{aligned}
& \dot{x}_{1}=\frac{1}{L_{1}}\left[d_{1} v_{P V}+\left(1-d_{1}\right)\left(v_{P V}-x_{3}\right)-r_{1} x_{1}\right] \\
& \dot{x}_{2}=\frac{1}{L_{2}}\left[d_{2} v_{F C}+\left(1-d_{2}\right)\left(v_{F C}-x_{3}\right)-r_{2} x_{2}\right] \\
& \dot{x}_{3}=\frac{1}{C}\left[\left(1-d_{1}\right) x_{1}+\left(1-d_{2}\right) x_{2}-\frac{x_{3}}{R_{L}}\right]
\end{aligned}
$$

\section{SECOND STAGE:}

$$
\begin{array}{r}
\dot{x}_{1}=\frac{1}{L_{1}}\left[\left(d_{1}-d_{4}\right) v_{P V}+d_{4}\left(v_{P V}+V_{B}\right)\right. \\
\left.+\left(1-d_{1}\right)\left(v_{P V}-x_{3}\right)-r_{1} x_{1}\right] \\
\dot{x}_{2}=\frac{1}{L_{2}}\left[\left(d_{2}-d_{4}\right) v_{P V}+d_{4}\left(v_{F C}+V_{B}\right)\right. \\
\left.+\left(1-d_{2}\right)\left(v_{F C}-x_{3}\right)-r_{2} x_{2}\right] \\
\dot{x}_{3}=\frac{1}{C}\left[\left(1-d_{1}\right) x_{1}+\left(1-d_{2}\right) x_{2}-\frac{x_{3}}{R_{L}}\right]
\end{array}
$$

\section{THIRD STAGE:}

$$
\begin{array}{r}
\dot{x}_{1}=\frac{1}{L_{1}}\left[\left(d_{1}-d_{4}\right) v_{P V}+d_{4}\left(v_{P V}+V_{B}\right)\right. \\
\left.+\left(1-d_{1}\right)\left(v_{P V}-x_{3}\right)-r_{1} x_{1}\right] \\
\dot{x}_{2}=\frac{1}{L_{2}}\left[\left(d_{2}-d_{4}\right) v_{P V}+d_{4}\left(v_{F C}+V_{B}\right)\right. \\
\left.+\left(1-d_{2}\right)\left(v_{F C}-x_{3}\right)-r_{2} x_{2}\right] \\
\dot{x}_{3}=\frac{1}{C}\left[\left(1-d_{1}\right) x_{1}+\left(1-d_{2}\right) x_{2}-\frac{x_{3}}{R_{L}}\right]
\end{array}
$$

\section{B. Energy Management Strategy (EMS)}

The EMS ensures that the HEV operates correctly and according to our objectives. The EMS is a vital part of every HEV because it generates various current and voltage references according to varying conditions and requirements. The controller only tracks the references it is given by the EMS. Hence it is very important that the EMS generates correct values of current and voltage references. The EMS must be designed to achieves the following objectives:

1) Generates PV source current reference value $i_{P V}^{r e f}$ according to the load demands.

2) Generates FC source current reference value $i_{F C}^{r e f}$ according to the load demands.

3) Generates output voltage reference value $V_{o}^{r e f}$ according to the requirements.

4) The converter operates in the correct mode according to the state of the battery and the load demands.

5) Load demand is fulfilled by the three sources.

However, the focus of this study is on the nonlinear control design of the selected HEV and that whether the HESS tracks the reference values set by EMS or not.

\section{Controller Design}

The mathematical model for each stage (3-e), (3-f), (3$\mathrm{g}$ ) is clearly a nonlinear model, as the model contains some terms in which the state variables $\left(x_{1}, x_{2}, x_{3}\right)$ are in product with the control inputs $\left(d_{1}, d_{2}, d_{3}, d_{4}\right)$. Since the control inputs are actually functions of the state variables, the resulting model is a nonlinear mathematical model. The dynamics and control of a nonlinear mathematical model are fully defined using a nonlinear control strategy. The control scheme used in this study is Lyapunov based control strategy. The nonlinear Lyapunov based control uses an energy like function called Lyapunov function candidate (LFC). The system is considered stable if the energy of the system is decreasing over time. In other words, if $V(x)$ is the LFC of a system, it is considered to be stable if,

$$
\dot{V}(x) \leq 0
$$

Since the control objectives for each stage are different, the control expression for each stage is also different and must be derived separately.

\section{A. For Stage 1}

In this stage only PV source and FC source operates whereas the battery is disconnected i.e. $i_{\text {batt }}=0$. The control objectives for stage 1 are as follows:

1) Minimize the error between input PV current i.e $i_{P V}=$ $i_{L_{1}}=x_{1} \&$ the reference $I_{P V}^{r e f}$.

2) Minimize the error between output voltage i.e $V_{o} \&$ the reference $V_{o}^{r e f}$.

According to our first objective, let's define the error $\left(e_{1}\right)$ as:

$$
e_{1}=x_{1}-I_{P V}^{r e f}
$$

Now regulating PV current means that the error $e_{1}$ should exponentially decay to zero. For this purpose we define its dynamics as follows:

$$
\dot{e}_{1}=-k_{1} e_{1}
$$

Where $k_{1}$ is a positive constant. Taking time derivative of (4-a) gives:

$$
\dot{e}_{1}=\dot{x}_{1}-\dot{I}_{P V}^{r e f}
$$

From the equations (3-e), we can write eq. (4-c) as:

$$
\dot{e}_{1}=\frac{1}{L_{1}}\left[d_{1} v_{P V}+\left(1-d_{1}\right)\left(v_{P V}-x_{3}\right)-r_{1} x_{1}\right]-\dot{I}_{P V}^{r e f}
$$

Using equation (4-b):

$$
-k_{1} e_{1}=\frac{1}{L_{1}}\left[d_{1} v_{P V}+\left(1-d_{1}\right)\left(v_{P V}-x_{3}\right)-r_{1} x_{1}\right]-\dot{I}_{P V}^{r e f}
$$

Solving for $d_{1}$ we get,

$$
d_{1}=\frac{1}{x_{3}}\left[-L_{1} k_{1} e_{1}-v_{P V}+r_{1} x_{1}+x_{3}+L_{1} \dot{I}_{P V}^{r e f}\right]
$$

Now, to complete the second objective, DC BUS voltage $V_{o}$ should track the reference $V_{o}^{r e f}$. Hence error $e_{3}$ is introduced as:

$$
e_{3}=x_{3}-V_{o}^{r e f}
$$


As we know that regulating PV current means that the error $e_{3}$ should exponentially decay to zero. For this purpose we define its dynamics as follows:

$$
\dot{e}_{3}=-k_{3} e_{3}
$$

Where $k_{3}$ is a positive constant. Taking time derivative of (4-f), and substituting the expression of $\dot{x}_{3}$ from (3-e)

$$
\dot{e}_{3}=\frac{1}{C}\left[\left(1-d_{1}\right) x_{1}+\left(1-d_{2}\right) x_{2}-\frac{x_{3}}{R_{L}}\right]-\dot{V}_{o}^{r e f}
$$

Since the reference voltage is a constant value, its derivative $\dot{V}_{o}^{r e f}=0$. Therefore, using eq. (4-f), we get:

$$
-k_{3} e_{3}=\frac{1}{C}\left[\left(1-d_{1}\right) x_{1}+\left(1-d_{2}\right) x_{2}-\frac{x_{3}}{R_{L}}\right]
$$

Now, solving for the control input $d_{2}$, we can obtain the control law for this stage as:

$$
d_{2}=\frac{1}{x_{2}}\left[C k_{3} e_{3}+\left(1-d_{1}\right) x_{1}+x_{2}-\frac{x_{3}}{R_{L}}\right]
$$

\section{B. For Stage 2}

In this stage all the sources: PV, FC and battery are providing power to the load. Therefore, $i_{\text {batt }}>0$. The control objectives for this stage can be given as:

1) Minimize the PV current error $e_{1}$ (eq. 4-a).

2) Minimize the error between input FC current i.e. $i_{F C}=i_{L_{2}}=x_{2} \&$ the reference $I_{F C}^{r e f}$.

3) Minimize the output voltage error $e_{3}$ (eq. 4-e).

According to our first objective, we have to eliminate the error between PV current and its reference. Using equations (4-a), (4-c) \& (4-b), but only this time we substitute the expression of $\dot{x}_{1}$ from stage 2 mathematical model equation (3-f), to get:

$$
\begin{aligned}
-L_{1} k_{1} e_{1} & =\left(d_{1}-d_{4}\right) v_{P V}+d_{4}\left(v_{P V}+V_{B}\right) \\
& +\left(1-d_{1}\right)\left(v_{P V}-x_{3}\right)-r_{1} x_{1}-\dot{I}_{P V}^{r e f}
\end{aligned}
$$

Further simplifying, we get:

$$
d_{1} x_{3}+d_{4} V_{B}=-k_{1} e_{1} L_{1}-v_{P V}+x_{3}+r_{1} x_{1}
$$

Now to complete the second objective, let us define an error $e_{2}$ as:

$$
e_{2}=x_{2}-I_{F C}^{r e f}
$$

To minimize the error $e_{2}$, the time derivative $\dot{e}_{2}$ should be negative. For this purpose we must define its dynamics so that $e_{2}$ would exponentially decay to zero with time. Therefore,

$$
\dot{e_{2}}=-k_{2} e_{2}
$$

Where $k_{2}$ is also a positive constant. Taking time derivative of (4-i) and using (3-f), we get:

$$
\begin{array}{r}
\dot{e}_{2}=\frac{1}{L_{2}}\left[\left(d_{2}-d_{4}\right) v_{P V}+d_{4}\left(v_{F C}+V_{B}\right)\right. \\
\left.+\left(1-d_{2}\right)\left(v_{F C}-x_{3}\right)-r_{2} x_{2}\right]-I_{F C}^{r e f}
\end{array}
$$

Using equation (4-j), it can be simplified as:

$$
d_{2} x_{3}+d_{4} V_{B}=-L_{2} k_{2} e_{2}-v_{F C}+x_{3}+r_{2} x_{2}
$$

For our third objective of stage 2, we have to eliminate the error between output voltage $x_{3}$ and its reference $V_{o}^{r e f}$. Taking time derivative of (4-e) and using (4-f) we can write:

$$
-k_{3} e_{3}=\dot{x}_{3}-\dot{V}_{o}^{r e f}
$$

Since the output voltage reference $V_{o}^{\text {ref }}$ is a constant, its derivative would be zero. Now substituting the expression of $\dot{x}_{3}$ from (3-f), we get:

$$
-k_{3} e_{3}=\frac{1}{C}\left[\left(1-d_{1}\right) x_{1}+\left(1-d_{2}\right) x_{2}-\frac{x_{3}}{R_{L}}\right]
$$

On further simplification, we get:

$$
-d_{1} x_{1}-d_{2} x_{2}=-k_{3} e_{3} C-x_{1}-x_{2}+\frac{x_{3}}{R_{L}}
$$

Considering equations (4-h), (4-k) and (4-1), we have a system of equations of three variables. It is further simplified to obtain the following control laws:

$$
\begin{aligned}
d_{2} & =\frac{k_{1} e_{1} L_{1} x_{1}+k_{2} e_{2} L_{2} x_{2}-v_{P V} x_{1}+v_{F C} x_{1}+r x_{1}^{2}}{-\left(x_{1}+x_{2}\right)\left(x_{3}\right)} \\
& +\frac{r x_{1} x_{2}-k_{3} e_{3} C x_{3}-x_{1} x_{3}-x_{2} x_{3}+\frac{x_{3}^{2}}{R_{L}}}{-\left(x_{1}+x_{2}\right)\left(x_{3}\right)} \\
d_{1} & =\frac{d_{2} x_{3}-k_{1} e_{1} L_{1}+k_{2} e_{2} L_{2}-v_{P V}+v_{F C}+r x_{1}-r x_{2}}{x_{3}} \\
d_{4} & =\frac{-k_{1} e_{1} L_{1}-v_{P V}+x_{3}-d_{1} x_{3}}{V_{B}}
\end{aligned}
$$

\section{For Stage 3}

The control objectives for this stage are similar to those for stage 2. Hence to achieve our first objective the first error $e_{1}$ is defined the same as defined in (4-a). Taking the time derivative of (4-a) and using the dynamic equations of stage 3 (eq. 3-g), we can write the resulting expression as:

$$
\begin{aligned}
-k_{1} e_{1} & =\left(\frac{1}{L_{1}}\right)\left(d_{3} v_{P V}+\left(d_{1}-d_{3}\right)\left(v_{P V}-V_{B}\right)\right. \\
& \left.+\left(1-d_{1}\right)\left(v_{P V}-x_{3}\right)-r_{2} x_{2}\right)-\dot{I}_{P V}^{r e f}
\end{aligned}
$$

Further simplification leads to:

$$
d_{1} V_{B}+d_{3} V_{B}+d_{1} x_{3}=-k_{1} e_{1} L_{1}-v_{P V}+x_{3}+r_{1} x_{1}
$$

Following the same procedure as done in the formulation of control laws for stage 2, the errors $e_{2}$ (eq. 4-i) and $e_{3}$ (eq. 4-e) are handled using the dynamic equations from stage 3 mathematical model (eq. 3-g). Therefore, the expression for $e_{2}$ is obtained using equations (4-i), (4-j) and (3-g) as:

$$
-d_{2} V_{B}+d_{3} V_{B}+d_{2} x_{3}=-k_{2} e_{2} L_{2}-v_{F C}+x_{3}+r_{2} x_{2}
$$

Similarly, using equations of error $e_{3}$ i.e. equations (4-e), (4-f) and using (3-g), the following expression is obtained:

$$
-d_{1} x_{1}-d_{2} x_{2}=-k_{3} e_{3} C-x_{1}-x_{2}+\frac{x_{3}}{R_{L}}
$$

Again following the steps done in the derivation of stage 2, the system of equations, comprising of equations (4-o), (4-p) 
and (4-q) is further simplified to obtain the control laws for stage 3 , given as:

$$
\begin{aligned}
d_{2} & =\frac{-k_{1} e_{1} L_{1} x_{1}+k_{2} e_{2} L_{2} x_{2}-v_{P V} x_{1}+v_{F C} x_{1}+r x_{1}^{2}}{V_{B} x_{1}+x_{2} V_{B}-x_{2} x_{3}-x_{1} x_{3}} \\
& +\frac{-r x_{1} x_{2}+V_{B} k_{3} e_{3} C x_{3}+V_{B} x_{1}+V_{B} x_{2}-x_{1} x_{3}-x_{2} x_{3}}{V_{B} x_{1}+x_{2} V_{B}-x_{2} x_{3}-x_{1} x_{3}} \\
& +\frac{-V_{B}+k_{3} e_{3} C x_{3}}{V_{B} x_{1}+x_{2} V_{B}-x_{2} x_{3}-x_{1} x_{3}} \\
d_{1} & =\frac{d_{2} x_{3}-k_{1} e_{1} L_{1}+k_{2} e_{2} L_{2}-v_{P V}}{-V_{B}+x_{3}} \\
& +\frac{v_{F C}+r x_{1}-r x_{2}-d_{2} V_{B}}{-V_{B}+x_{3}} \\
d_{4} & =\frac{-k_{1} e_{1} L_{1}-v_{P V}+x_{3}+r_{1} x_{1}+d_{1} V_{B}-d 1_{x} 3}{V_{B}}
\end{aligned}
$$

\section{Stability AnAlysis}

As discussed earlier in section IV, the stability of the system, operating in stage 1, can be proved LFC, given as:

$$
V=\frac{1}{2} e_{1}^{2}+\frac{1}{2} e_{3}^{2}
$$

We need to make the $\dot{V}$ negative definite, in order to make the system asymptotically stable. Taking derivative of (5-a), we get

$$
\dot{V}=e_{1} \dot{e}_{1}+e_{3} \dot{e}_{3}
$$

Using (4-b) and (4-f), we get

$$
\dot{V}=-k_{1} e_{1}^{2}-k_{3} e_{3}^{2}
$$

Since constants $k_{1}$ and $k_{2}$ are positive, which proves that:

$$
\dot{V} \leq 0, \forall x \in \mathbb{R}^{3}
$$

Hence for stage 1 , the closed loop system is globally asymptotically stable.

For stage 2 and 3, the LFC can be given as:

$$
V=\frac{1}{2} e_{1}^{2}+\frac{1}{2} e_{2}^{2}+\frac{1}{2} e_{3}^{2}
$$

Taking the time derivative of (5-b), we get:

$$
\dot{V}=e_{1} \dot{e}_{1}+e_{2} \dot{e}_{2}+e_{3} \dot{e}_{3}
$$

From (4-b), (4-j) and (4-f), we get:

$$
\dot{V}=-k_{1} e_{1}^{2}-k_{2} e_{2}^{2}-k_{3} e_{3}^{2}
$$

Since $k_{1}, k_{2} \& k_{3}$ are positive constants, $\dot{V}$ is negative definite. Hence the closed loop system is globally asymptotically stable for stages $2 \& 3$.

\section{Simulation Results}

The HEV system is simulated to validate the performance of the proposed nonlinear controller. The DC reference voltage $\left(V_{o}^{r e f}\right)$ is taken as $350 \mathrm{~V}$. Therefore one of the controller objectives is to regulate the DC bus to $350 \mathrm{~V}$. PV and FC sources are modeled as current dependent sources. The current references $i_{P V}^{r e f} \& i_{F C}^{r e f}$ are taken different in each stages. In stage 1 , there is only one current reference: $i_{P V}^{r e f}$ because as explained in IV-A, our objectives are to control only the $i_{P V}^{r e f}$ and $V_{o}^{r e f}$. The reference values for each stage is given in Table I. The DC-DC converter parameters are listed in Table II. The controller gains for each stage are evaluated using hit-and-trial method and are listed in Table III. The control laws for each stage are built in separate blocks. The stages are differentiated by the battery current state $\left(i_{\text {batt }}\right)$ as shown in (3-a).

TABLE I. SET REFERENCE VALUeS

\begin{tabular}{|l|c|c|r|}
\hline Reference values & Stage 1 & Stage 2 & Stage 3 \\
\hline \hline$i_{P V}^{r e f}(\mathrm{~A})$ & 16.25 & 21 & 5.3 \\
\hline$i_{F C}^{r e f}(\mathrm{~A})$ & NIL & 7.5 & 23 \\
\hline$V_{o}^{r e f}(\mathrm{~V})$ & 350 & 350 & 350 \\
\hline
\end{tabular}

TABLE II. COMPONENTS VALUES

\begin{tabular}{|l|c|r|}
\hline Parameter & Notation & \multicolumn{1}{|c|}{ Value } \\
\hline \hline Inductor & $L_{1}, L_{2}$ & $4 \mathrm{e}-3$ \\
\hline Capacitor & $C$ & $200 \mathrm{e}-6$ \\
\hline
\end{tabular}

TABLE III. Control Design PARAMETERS

\begin{tabular}{|l|c|c|r|}
\hline Stage & $k_{1}$ & $k_{2}$ & $k_{3}$ \\
\hline \hline Stage 1 & 100 & 100000 & 100000 \\
\hline Stage 2 & NIL & 10 & 10 \\
\hline Stage 3 & 10 & 100 & 100 \\
\hline
\end{tabular}

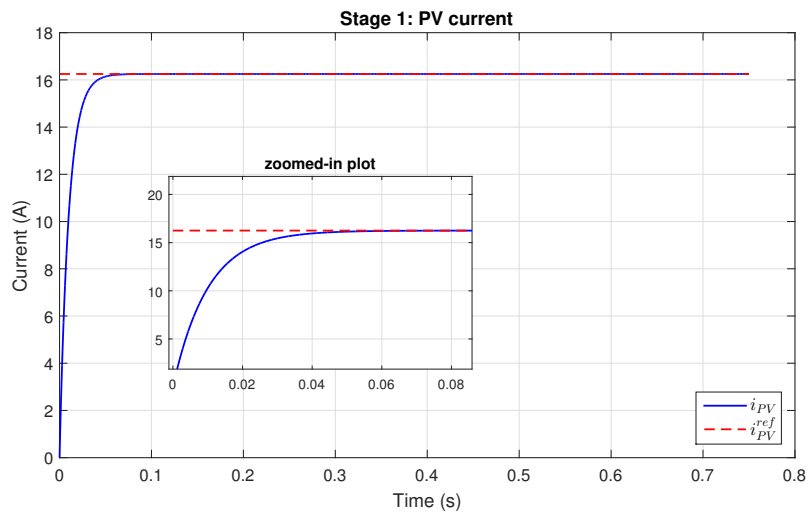

Fig. 6. Plot of $i_{P V}$ for stage 1 , with $i_{P V}^{r e f}=16.25 A$

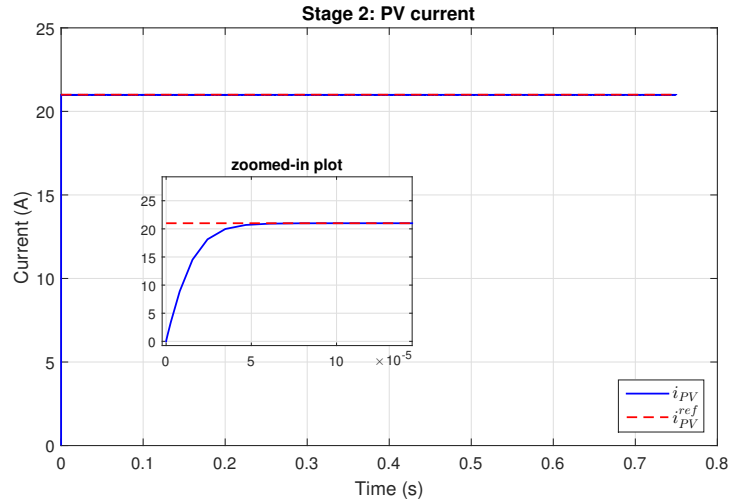

Fig. 7. Plot of $i_{P V}$ for stage 2, with $i_{P V}^{r e f}=21 \mathrm{~A}$ 


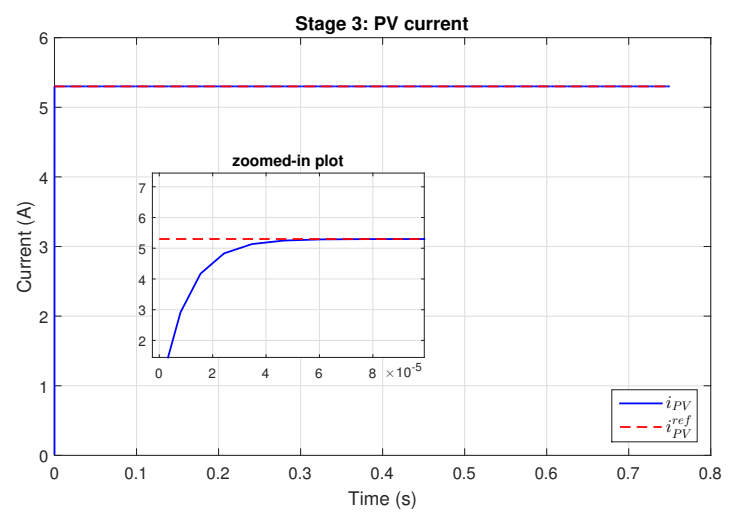

Fig. 8. Plot of $i_{P V}$ for stage 3, with $i_{P V}^{r e f}=5.3 A$

The HESS and the proposed controller are simulated for a total time of 0.75 seconds. As one can see, the PV current $\left(i_{P V}\right)$ tracks its reference value perfectly for all the three stages that is $16.25 \mathrm{~A}$ for stage 1 in Fig. 6, 21A for stage 2 in Fig. 7 and 5.3A for stage 3 in Fig. 8 . A slight deviation is observed in the transient response, however, the response settled down very quickly. Same behavior is observed in the FC current i.e. the Fuel Cell current is perfectly tracked that is $7.5 \mathrm{~A}$ for stage 2 in Fig. 9 and 23A for stage 3 in Fig. 10 and output voltage $\left(V_{o}\right)$ waveform (Fig. 11), where the response took a little time to settle down. The transient time for the $i_{F C}$ is observed to be around 0.4 seconds, which is sufficient for the vehicular operation. Since the output voltage $\left(V_{o}\right)$ has been set to track a constant reference value, in all the stages (see Table I), a constant output voltage of $350 \mathrm{~V}$ has been observed in all the converter stages. It is important to note here that the output load value is not constant in this simulation. From Fig. 12, it can be seen that the output load is set to vary from $10 \Omega$ to $80 \Omega$ with a linear change of $35 \Omega / \mathrm{s}$. Hence it can be concluded that the proposed system is performing correctly under varying load conditions, which is the primary objective of our control scheme. To quantify the controller's performance, the settling time is recorded for each operating stage. The settling time is the time, the response of a system takes to reach $90 \%$ of its final value. It is an important, quantifiable performance measure for a controller. Following values of settling time has been recorded for each stage of the converter:

\section{1) Stage 1 :}

- $0.107 \mathrm{~s}$ for PV current.

- $1.363 \mathrm{~s}$ for DC-link voltage.

\section{2) Stage 2 :}

- $0.002 \mathrm{~s}$ for PV current.

- 0.926 s for FC current.

- 0.135 s for DC-link voltage.

\section{3) Stage 3 :}

- 0.002 s for PV current.

- $0.941 \mathrm{~s}$ for FC current.

- 0.135 s for DC-link voltage.

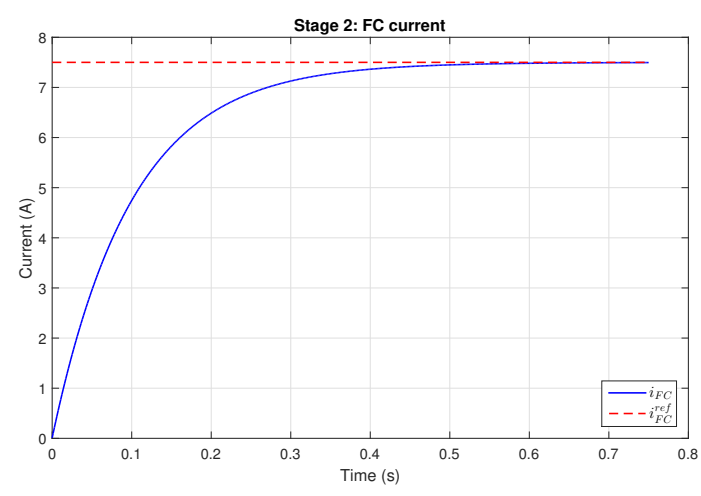

Fig. 9. Plot of $i_{F C}$ for stage 2, with $i_{F C}^{r e f}=7.5 \mathrm{~A}$

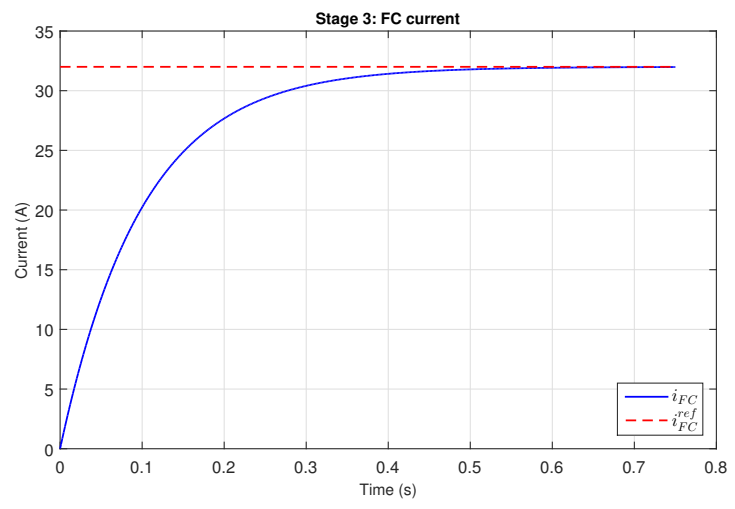

Fig. 10. Plot of $i_{F C}$ for stage 3, with $i_{F C}^{r e f}=32 \mathrm{~A}$

\section{COMPARISON WITH PI-CONTROL}

PI-control has been applied on the same HESS in [29]. The technique was based on decoupling network. Two types of decoupling networks have been utilized to design a feedback converter. For proper comparison, reference values and converter parameters are kept the same. The only change in parameters from previous simulation in the load resistance

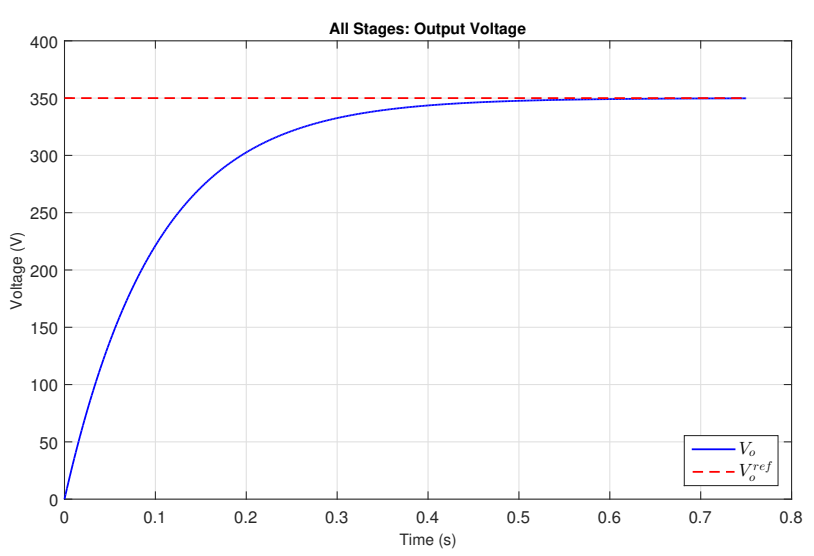

Fig. 11. Plot of Output Voltage $V_{o}$ tracking $V_{o}^{\text {ref }}=350 \mathrm{~V}$, constant for all the stages 


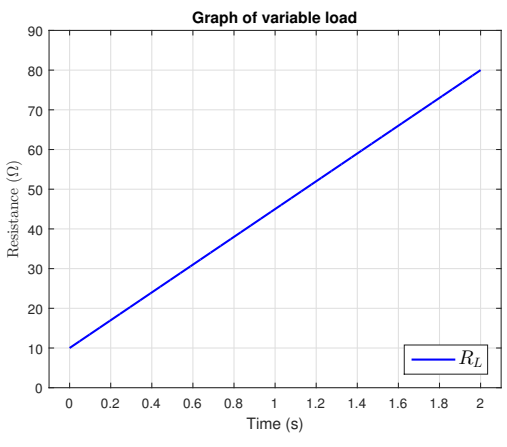

Fig. 12. Plot of Variable load $R_{L}$

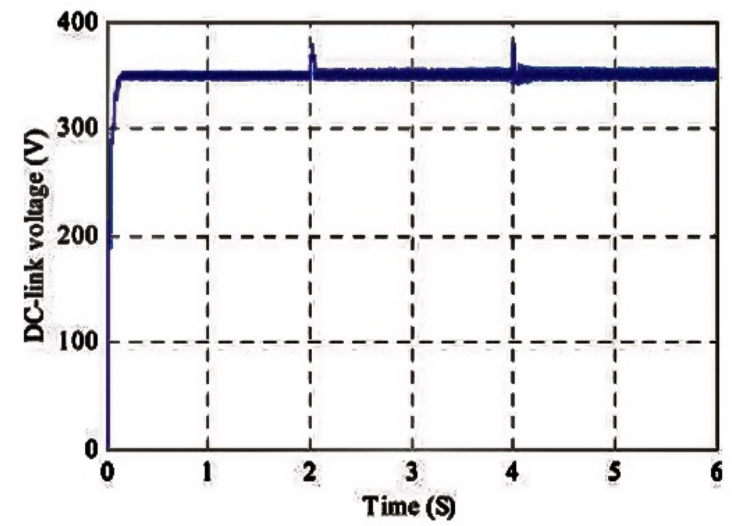

Fig. 13. Output voltage $V_{o}$ with PI control

value, which is a constant: $R_{L}=49 \Omega$.

Fig. 13 and 14 show the PI-control based HESS [29]. Overshoot and ripples of large magnitudes can be observed at the times when the reference currents are changed (see Fig. 14). Therefore, the advantages of the proposed control scheme over the PI-control, can be summarized in the following points:

1) No overshoot was observed even when the reference and load varied.

2) No steady state error was found in PV current and FC current in all the stages.

3) No steady state error in output voltage was observed.

4) Very small current ripples were observed in all the source currents (PV, FC \& battery).

\section{CONCLUSION}

A Lypunov based nonlinear control technique is applied on a MIMO HEV system. The input sources are PV module, PEMFC and high voltage lithium-ion battery. The converter topology has four switches which are independently controlled. The DC-DC converter operation is divided into three stages, differentiated by the state of battery current. A state-averaged nonlinear mathematical model of the HEV has been developed and a Lyapunov-based non-linear control scheme has been applied to achieve current and voltage regulation of each source in each stage. The proposed system is simulated on

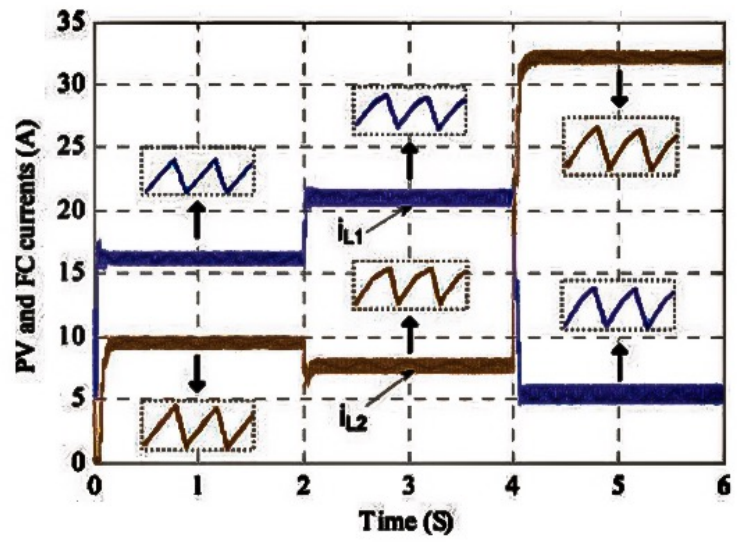

Fig. 14. Plot of source currents with PI control

MATLAB/Simulink to observe the controller's performance. The proposed nonlinear controller is found to be better in terms of current tracking, DC-bus voltage and load regulation, when compared with a PI-based controller. Therefore, by observing its performance and its effectiveness, one can conclude that the proposed controller is a better choice for applications such as HEVs, where multiple energy sources are involved.

\section{REFERENCES}

[1] Haifeng Wang. A boost converter design with low output ripple based on harmonics feedback. arXiv preprint arXiv:1901.10020, 2019.

[2] Fanchao Liao, Eric Molin, Harry Timmermans, and Bert van Wee. Consumer preferences for business models in electric vehicle adoption. Transport Policy, 73:12-24, 2019.

[3] JA Domínguez-Navarro, R Dufo-López, JM Yusta-Loyo, JS Artal-Sevil, and JL Bernal-Agustín. Design of an electric vehicle fast-charging station with integration of renewable energy and storage systems. International Journal of Electrical Power \& Energy Systems, 105:4658, 2019.

[4] M. S. A. Chowdhury, K. A. A. Mamun, and A. M. Rahman. Modelling and simulation of power system of battery, solar and fuel cell powered hybrid electric vehicle. In 2016 3rd International Conference on Electrical Engineering and Information Communication Technology (ICEEICT), pages 1-6, Sept 2016.

[5] Khalil Amine. E-fuel system: a conceptual breakthrough for energy storage. Science Bulletin, 64(4):227-228, 2019.

[6] Y. T. Teng and F. C. Wang. Cost analyses and optimization of a pemfc electric vehicle model. In 2016 IEEE/SICE International Symposium on System Integration (SII), pages 887-892, Dec 2016.

[7] Dragan W Maksimovic, Khurram K Afridi, Regan A Zane, Gregory L Plett, and Michael Scott Trimboli. Heterogeneous energy storage system and method of controlling a heterogeneous energy storage system, February 28 2019. US Patent App. 16/079,957.

[8] Hassan Fathabadi. Combining a proton exchange membrane fuel cell (pemfc) stack with a li-ion battery to supply the power needs of a hybrid electric vehicle. Renewable energy, 130:714-724, 2019.

[9] Hanqing Wang, Arnaud Gaillard, and Daniel Hissel. A review of dc/dc converter-based electrochemical impedance spectroscopy for fuel cell electric vehicles. Renewable Energy, 2019.

[10] Ahmed Fathy, Hegazy Rezk, and Ahmed M Nassef. Robust hydrogenconsumption-minimization strategy based salp swarm algorithm for energy management of fuel cell/supercapacitor/batteries in highly fluctuated load condition. Renewable Energy, 139:147-160, 2019.

[11] J. Chen, C. Xu, C. Wu, and W. Xu. Adaptive fuzzy logic control of fuel-cell-battery hybrid systems for electric vehicles. IEEE Transactions on Industrial Informatics, 14(1):292-300, Jan 2018. 
[12] Kathleen Araújo, Jean Léon Boucher, and Omkar Aphale. A clean energy assessment of early adopters in electric vehicle and solar photovoltaic technology: Geospatial, political and socio-demographic trends in new york. Journal of Cleaner Production, 216:99-116, 2019.

[13] Ankit Gupta, Yogesh K Chauhan, and Rupendra Kumar Pachauri. A comparative investigation of maximum power point tracking methods for solar pv system. Solar energy, 136:236-253, 2016.

[14] Jisun Kim, Chih-Jen Yu, M. Khammuang, J. Lui, A. Almujahid, and T. Daim. Forecasting battery electric vehicles. In 2017 IEEE Technology Engineering Management Conference (TEMSCON), pages 199-208, June 2017.

[15] Hammad Armghan, Iftikhar Ahmad, Naghmash Ali, Muhammad Faizan Munir, Saud Khan, and Ammar Armghan. Nonlinear controller analysis of fuel cell-battery-ultracapacitor-based hybrid energy storage systems in electric vehicles. Arabian Journal for Science and Engineering, 43(6):3123-3133, 2018.

[16] Lia Kouchachvili, Wahiba Yaïci, and Evgueniy Entchev. Hybrid battery/supercapacitor energy storage system for the electric vehicles. Journal of Power Sources, 374:237-248, 2018.

[17] BM Sanghavi, C Tejaswini, and Venkateshappa Venkateshappa. Dc/dc boost converter using dsp controller for fuel cell. Perspectives in Communication, Embedded-systems and Signal-processing-PiCES, 2(10):248-251, 2019.

[18] D. Foito, M. Gaspar, and V. F. Pires. Road motion control electric vehicle with speed and torque observer. In 2013 International Conference on New Concepts in Smart Cities: Fostering Public and Private Alliances (SmartMILE), pages 1-6, Dec 2013.

[19] Ottorino Veneri, Clemente Capasso, and Stanislao Patalano. Experimental investigation into the effectiveness of a super-capacitor based hybrid energy storage system for urban commercial vehicles. Applied Energy, 227:312-323, 2018.

[20] H. Yin, C. Liu, D. You, J. Zhao, Y. Wu, and Z. Ling. A new isolation control of three-port active converters for electric vehicles. In 2017 IEEE Conference on Energy Internet and Energy System Integration (EI2), pages 1-4, Nov 2017

[21] S. Das, K. M. Salim, and D. Chowdhury. A novel variable width pwm switching based buck converter to control power factor correction phenomenon for an efficacious grid integrated electric vehicle battery charger. In TENCON 2017 - 2017 IEEE Region 10 Conference, pages 262-267, Nov 2017.

[22] K. C. Manjunatha and Manjesh. Design and development of flyback converter with buck-boost regulator for dc motor used in electric vehicle for the application of renewable energy. In 2017 International Conference on Circuit, Power and Computing Technologies (ICCPCT), pages 1-4, April 2017.

[23] Martin Batliner, Oliver König, Stefan Jakubek, and Günter Prochart. Method and controller for model predictive control of a multi-phase dc/dc converter, February 26 2019. US Patent App. 10/216,153.
[24] Xinan Zhang, Benfei Wang, Ujial Manandhar, Hoay Beng Gooi, and Gilbert Foo. A model predictive current controlled bidirectional threelevel $\mathrm{dc} / \mathrm{dc}$ converter for hybrid energy storage system in dc microgrids. IEEE Transactions on Power Electronics, 34(5):4025-4030, 2019.

[25] Apparao Dekka, Bin Wu, Venkata Yaramasu, Ricardo Lizana Fuentes, and Navid R Zargari. Model predictive control of high-power modular multilevel convertersan overview. IEEE Journal of Emerging and Selected Topics in Power Electronics, 7(1):168-183, 2019.

[26] B. N. Kommula and V. R. Kota. Performance evaluation of hybrid fuzzy pi speed controller for brushless dc motor for electric vehicle application. In 2015 Conference on Power, Control, Communication and Computational Technologies for Sustainable Growth (PCCCTSG), pages 266-270, Dec 2015.

[27] Tapas Kumar Mohapatra, Asim Kumar Dey, Krushna Keshab Mohapatra, and Binod Sahu. A novel non-isolated positive output voltage buck-boost converter. World Journal of Engineering, 2019.

[28] R. Das and M. A. UddinChowdhury. Pi controlled bi-directional dcdc converter (bdddc) and highly efficient boost converter for electric vehicles. In 20163 rd International Conference on Electrical Engineering and Information Communication Technology (ICEEICT), pages 1-5, Sept 2016.

[29] R. R. Ahrabi, H. Ardi, M. Elmi, and A. Ajami. A novel step-up multiinput dc x2013; dc converter for hybrid electric vehicles application. IEEE Transactions on Power Electronics, 32(5):3549-3561, May 2017.

[30] R. K. Vardhan, T. Selvathai, R. Reginald, P. Sivakumar, and S. Sundaresh. Modeling of single inductor based battery balancing circuit for hybrid electric vehicles. In IECON 2017 - 43rd Annual Conference of the IEEE Industrial Electronics Society, pages 2293-2298, Oct 2017.

[31] Hui Peng, Junzheng Wang, Wei Shen, Dawei Shi, and Yuan Huang. Compound control for energy management of the hybrid ultracapacitorbattery electric drive systems. Energy, 2019.

[32] P. Swain and D. Jena. Modeling, simulation amp; optimal control of non-linear pem fuel cell with disturbance input. In 2015 International Conference on Innovations in Information, Embedded and Communication Systems (ICIIECS), pages 1-7, March 2015.

[33] Yu Wu, Yigeng Huangfu, Rui Ma, Alexandre Ravey, and Daniela Chrenko. A strong robust dc-dc converter of all-digital high-order sliding mode control for fuel cell power applications. Journal of Power Sources, 413:222-232, 2019.

[34] A. K. Gupta and R. Saxena. Review on widely-used mppt techniques for pv applications. In 2016 International Conference on Innovation and Challenges in Cyber Security (ICICCS-INBUSH), pages 270-273, Feb 2016.

[35] H. El Fadil, F. Giri, J. M. Guerrero, and A. Tahri. Modeling and nonlinear control of a fuel cell/supercapacitor hybrid energy storage system for electric vehicles. IEEE Transactions on Vehicular Technology, 63(7):3011-3018, Sept 2014. 